\title{
Conserving Biodiversity in the Face of Climate Change
}

\author{
Harry Clarke
}

$\mathrm{M}$ ost climate scientists accept that environmentally-damaging, anthropogenic, global warming has been a reality over the past century and that, unless societies reduce their greenhouse gas emissions, warming will become an increasingly serious global concern. Even with active greenhouse gas management policies in place it is also widely agreed that global warming will continue because of lags in climate generation. This has led to policies being developed which promote adaptation to the effects of global warming as it is expected to unfold. These policies accept that future global warming will be a reality and seek to learn to live with it.

One class of adaptation strategies, of concern to Australia, relate to biodiversity resources. Biodiversity has intrinsic value if citizens value species and habitats that exist per se. Biodiversity also has instrumental value in improving the quality of life of citizens who consume the direct service flows (such as aesthetic values) stemming from it and, indirectly, through its role in ensuring a reliable supply of agricultural, water resource and other outputs. Biodiversity resources are already being lost because of human land use impacts such as land clearing and urbanisation. Climate change can be expected to exacerbate the rate of such losses in the sense that:

Climate change is projected to affect individual organisms, populations, species distributions, and ecosystem conservation and function both directly (for example, through increases in temperature and changes in precipitation and in the case of marine and coastal ecosystems also changes in sea level and storm surges) and indirectly (for example, through climate changing the intensity and frequency of disturbances such as wildfires). Processes such as habitat loss, modification and fragmentation, and the introduction of non-native species will affect the impacts of climate change. (Intergovernmental Panel on Climate Change, 2002:1).

This paper shows how to determine economically efficient public policies to reduce the impact of climate change on the range and richness of Australian biodiversity. It emphasises issues of limiting species extinctions to advance the community's demands for biodiversity conservation. Avoiding extinctions alone is, however, a narrow conservation perspective. More generally we think of policies to improve the resilience of Australian biodiversity as a whole to climate change, including the facilitation of species relocations and the prevention of unsought species invasions.

Harry Clarke is Professor of Economics, Department of Economics and Finance, La Trobe University. 
The policy design task addressed is: to promote inevitably slow biodiversity adaptation responses to rapid climate change when costs and benefits of adaptation are uncertain, as are the physical and environmental effects of global warming; when there is controversy over the discount rate used to weigh the welfare of future generations; when damages associated with biodiversity destruction are nonlinear, involving irreversibilities and threshold effects; and finally, when policy makers must address uncertain policy objectives over distant time horizons.

This is a complex policy design task because of the interaction between the uncertain effects observed and possible irreversibilities such as species extinctions and habitat destruction. An analysis of such issues is provided based on 'real options' theory.

The next section provides background information on the biodiversity conservation problem posed and articulates the factors complicating its resolution. The subsequent section examines policy developments in Australia and articulates the approach provided by the Natural Resource Ministerial Council (NRMC, 2004). The paper then concludes with some final remarks.

\section{Global Warming and Biodiversity Conservation}

Most of Australia will be likely to warm by between $1-6^{\circ} \mathrm{C}$ over 1990 levels by 2070. Annual rainfall is likely to fall in the south and southeast where population and agricultural production are concentrated and evaporation will increase. Some sparsely-populated inland and north western areas will have moister summers (Preston and Jones, 2007). To provide perspective, with a $4-6^{\circ} \mathrm{C}$ increase in temperature, Melbourne's climate would resemble that of Moree in northern NSW. The forecast climatic effects could be very significant. Globally, a $6^{\circ} \mathrm{C}$ average temperature increase matches the average increase experienced since the last ice age (Wolfson and Schneider, 2002:16).

\section{Climatic uncertainty}

Precise climatic effects are complex and difficult to forecast. Meteorology suggests the relation between greenhouse gas concentrations and climate is uncertain. There is also uncertainty concerning effects on climate of measures to control emissions partly because the high natural variability of climate masks slowly-evolving induced climate trends. Furthermore, Australia spans regions from the tropics to the mid-latitudes with a range of climatic conditions and with high climatic variability. The highly variable climate arises partly because of the EI Niño Southern Oscillation which brings about the poet Dorothy Mackellar's description of eastern Australia's climate as one of 'droughts and flooding rains'. Climate change can intensify extreme climatic outcomes with increased intensity and frequency of droughts, heavy rains, floods and cyclones. With higher temperatures, too, there will be more heatwaves and fewer frosts. Impacts on specific average rainfall patterns are highly uncertain with reduced rainfall in the southwest but with either increased or decreased rainfall in northern and eastern Australia. Pittock (2003; 2005:256-257) provides further information. 
Thus while climate change is generated by global greenhouse gas emissions, its effects will differ widely by region (Wolfson and Schneider, 2002:36-40). But while information on general trends in climate is useful, species conservation concerns often involve analysing specific habitats in small geographic regions that are subject to localised climatic and environmental experiences. Conservation biologists will inevitably be forced to place weight on aggregated, uncertain climate forecasts.

A major initial observation is therefore simply that the effects of climate change on Australia are geographically diverse and uncertain in terms of both specific temperature and rainfall effects.

\section{Environmental uncertainty}

While most climate change science has focused on the impacts of climate change for human life, a growing literature addresses the consequences for non-human life and particularly for biodiversity. Even with gradual climate change, isolated populations of flora and fauna face difficulties in adapting to, or relocating away from, changed climates because human fragmentation of landscapes by agriculture and urban developments limits relocations. If, as expected, substantial climatic changes occur over a short period, such as 50-100 years - on a geological timescale this is abrupt - effects will be severe, particular since the current global climate is one of the warmest experienced over the past two million years (Overpeck, Cole and Bartlein, 2005). Climatic disturbances will increase rates of species loss and provide opportunities for the establishment of new invasive species.

A possible extreme environmental consequence of climate change globally is an ensuing wave of species extinctions and a destruction of biodiversity values. Thomas et al (2004) estimate that, in regions covering one fifth of the earth, 1537 per cent of plant and animal species could face extinction by 2050 should a middle-of-the-road scenario for increased emissions eventuate. If emissions are on the high side, the range jumps to 21-52 per cent. Note the wide range in these estimates and their sensitivity to assumptions regarding mitigation responses. The Stern Review (2006) broadly endorsed these estimates: a warming of $2^{\circ} \mathrm{C}$ was expected to leave $15-40$ per cent of the world's currently extant species extinct.

The Climate Change Network, at their website, draw on studies from 19952001 to compile a list of ninety Australian animal species at risk from climate change (see http://www.cana.net.au/bush/aus_animals.htm). Most species identified are currently threatened species. What is required is a more general indication of the resilience of species and habitats to climate change on which there is only partial information. As a guide, species with limited climatic ranges (such as endemic mountain species or species on islands or coastal areas) that live within restricted habitats are most vulnerable to extinction while those with greater ability to relocate living in extensive, non-patchy ranges are less threatened (NRMC, 2004).

For example, Hughes, Westoby and Cawsey (1996) examine the distribution of 819 species of eucalyptus, the major tree type characterising the Australian landscape. The majority of these individual species occupy small discrete regions 
defined by narrow temperature zones. More than 200 species have ranges spanning $1^{\circ} \mathrm{C}$ while 82 span just $2^{\circ} \mathrm{C}$. If Australia's temperature should rise by $3^{\circ} \mathrm{C}$ half of Australia's eucalypts would grow outside their current zone suggesting the potential for a non-resilient response.

Knowledge of climate change effects on biodiversity is limited because of uncertainty about the effectiveness of natural adaptive responses, the role of geographical fragmentation of ecosystems and the assault that might be launched on certain areas by invading exotic and natural species. Species are unlikely to relocate in unison, with many species responding individually. With substantial time lags and periods of reorganisation, species assemblages may develop that are less diverse and more 'weedy', comprising species that are highly mobile and which can re-establish quickly (Intergovernmental Panel on Climate Change, 2002:17).

Most available resilience information is very partial and species-cum-habitat specific. Given ecosystem complexities, uncertainty is therefore intrinsic to analysing effects of climate change on species and habitat resilience. Pittock (2003:168) states:

... there is relatively little specific information about the long-term capacity for and rates of adaptation of ecosystems in Australia that can be used to predict likely outcomes. Therefore, a large degree of uncertainty inevitably exists about the future of the Australian natural ecosystems under climate change.

Our second major observation is also simple. The specific effects of climate change on biodiversity are highly uncertain.

\section{Policy objective uncertainty}

Finally, it is important to clarify what the policy objectives are with respect to conserving biodiversity. These are complex partly because the 'biodiversity' idea is a pseudo-cognate concept (Gaston, 1996:1). Different users of this term have distinct referents in mind (genes, different species concepts, populations, biomes) but use the term as if it had a common meaning. It is intrinsically difficult to formulate policies given such an ambiguous notion.

Even ignoring definitional niceties, the development of biodiversity conservation strategies in Australia, as in most countries, has been partly ad hoc and partly based on pursuit of clear conservation outcomes. It is acknowledged, for example, that land with high agricultural value (for example, grassland habitat) has been under-supplied for conservation.

With respect to biodiversity conservation per se, specific objectives of policy are diffuse and numerous (Environment Australia, 2001). Policies sometimes seek to limit extinctions, sometimes to retain representative habitats, and sometimes to perform the uncertain role biodiversity plays in maintaining ecosystem structure, functioning and productivity. In seeking strategies to deal with exogenous climate changes simple objectives are not being addressed.

Moreover, as benefits and costs from biodiversity conservation are distributed into the distant future the inter-temporal valuation issue of choosing a discount rate arises in choosing between conservation options. The disagreement and uncertainty over assigning discount rates becomes crucially important in problems 
with long-term time horizons. If discount rates are significantly greater than zero, say five per cent, and if costs of acting are borne now while benefits accrue in the distant future, then on the basis of cost-benefit analysis, the best policy is to do nothing since discounted benefits may not justify costs. Conserving a species worth $\$ 1$ billion in 200 years is worth only $\$ 58,000$ today at a discount rate of five per cent. Moreover, intergenerational arguments such as placing significant weight on the environment we hope to transfer to our children, suggest discounting at a low rate. Pindyck (2007) shows that being uncertain about the discount rate itself means that the rate used should be set at less than the expected future discount rate in the absence of uncertainty with the reduction increasing as the planning time horizon increases. For long-term planning, setting a discount rate close to zero - as done by the Stern Review (2006) - for other climate change tasks is not implausible.

\section{Irreversibilities}

Important irreversibilities impact on policy-making. These pull in opposite directions both in terms of desired policy intensities and the timing of interventions. They substantially complicate policy planning.

Species loss effects, in particular extinctions, are irreversible. According to the 'real options' literature this creates incentives to adopt active adaptation strategies early even if benefits from doing so fall somewhat short of costs incurred. The existence of the possibility of a future benefit from not allowing a species to go extinct provides an 'option value' rationale for species protection that reflects the irreversible loss of options implied by extinctions. This is the core idea of the 'real options' approach to irreversible investments under uncertainty (Dixit and Pindyck, 1994) with such option values providing a bias towards early adoption of policy and for greater policy stringency.

Sunk cost effects arise because policies to deal with climate change problems impose sunk costs on society. For example, investing in captive-breeding programs or the translocation of species are expensive discrete investments that are not recoverable should the investments prove unwise. Such would be the case, for example, if long-term conservation costs turn out to be higher than expected while long term benefits are lower. This provides a motivation to wait for better information before undertaking investment in biodiversity protection. Cost benefit analysis which accounts for this 'value of waiting' will be biased toward postponing adoption of activist policy and for reducing policy stringency.

Combining these irreversibilities suggests that, depending on their relative importance, uncertainty can sometimes increase and sometimes decrease both the timing and extent of desired conservation effort. Without good empirical evidence, which is lacking, there is no simple way of making an a priori judgment of the relative size of 'species loss' and 'sunk cost' effects. Some literature, based on plausible though invented data, suggests 'sunk cost' effects are relatively strong, thus establishing a case for deferred, low-intensity investments rather than high-intensity conservation policies now (Pindyck, 2000; 2002). 


\section{Nonlinearities and thresholds}

The case for emphasising 'sunk cost' irreversibilities is tempered by the prospects of non-linear environmental damage responses to climate change once uncertain critical thresholds occur (Pittock, 2005:99-105). Such non-linearities can be accounted for by allowing for catastrophic risks of substantial damages. A biodiversity example might be widespread species extinctions while, at the climate level, catastrophic risks include possible rapid deglaciation of the polar ice sheets or collapse of the conveyor belt circulation of ocean currents in the North Atlantic. It should be noted that, given the complexity of environmental systems, catastrophic risks could also take the form of 'unknown unknowns' or currently unanticipated possible consequences (Grant and Quiggin, 2006). Then previously undiscovered consequences of climate change for biodiversity may be discovered in the future and events previously regarded as impossible may turn out to be possible. We may also find out that we know less than we thought we did.

Clarke and Reed (1994) show that, if the degree of risk of catastrophic collapse is strongly related to the extent of policy intervention, a critical lack of conservation effort brings about a wave of costly extinctions, greater stringency in control is sought. This provides a case for pursuing 'safety first' options. If, however, greater risk is expected that is unrelated to the extent of policy intervention then, by a triage argument, less should be expended on protecting species since their value has unalterably fallen.

Intuition suggests that a case for early action is also motivated by standard arguments emphasising the increasing value of 'natural' relative to 'human-made' capital as technical progress proceeds. Human-made capital can be augmented and replaced while natural capital cannot. Also, with increasing wealth, if it is supposed that demands for biodiversity conservation are a luxury good, so higher conservation standards are demanded with increased affluence, there is again an argument for early adoption of adaptation policies to improve biodiversity resilience (Krutilla, 1967).

\section{Summing up}

There is uncertainty about the scale of climate change, about climate change impacts on biodiversity, and on what adaptive policy should seek to achieve. Significant irreversibilities add complexity to the planning task. Formal economic model-building can help sort out the qualitative role of these complicating factors and can suggest sensible policies.

As a general matter, the high uncertainty in analysing this policy task suggests a motive for investing in providing timely information on the likely future extent of climatic effects and consequent biodiversity impacts, and for monitoring current environmental responses to climate change. Also, the substantial risks suggest the case for a diversified policy mix, not an emphasis on a narrow range of options. Unless there are overwhelmingly large fixed costs, a number of policy responses need to be sought and backup 'insurance' options pursued lest major policies fail. For example, with respect to endangered species protection, one might simultaneously seek to strengthen protection accorded in current 
environments, to translocate that species to new environments, and to perhaps also develop a captive breeding response as insurance.

Uncertainty needs to be incorporated into formal decision models by attaching Bayesian probabilities to anticipated outcomes with account taken for possible surprise events. Probabilities - however imprecise - should be assigned using expert judgement even if costs and benefits assigned to the outcomes reflect policy-maker or community values rather than those of the experts.

The general policy prescription involves increased investment in biodiversity conservation to reflect the increased risk that this valuable community asset is now exposed to. In part this investment reflects the fact that species will endogenously relocate as climate change proceeds. Thus investment effort will need to be devoted to improving the resilience of existing conservation resources, the adaptability of new areas as receptor sites for new species and towards preventing unwanted species invasions.

\section{A Policy Framework}

Australian governments through the Natural Resource Ministerial Council (NRMC, 2004) have prepared an 'action plan' for addressing climate change impacts on Australian biodiversity. The NRMC's intent is for each state and territory to undertake specific initiatives to implement this plan and for the Commonwealth to coordinate efforts. The plan splits into three undertakings that are broadly consistent with the framework above. They involve investing in information and in minimising the biodiversity impacts of climate change. An additional operational issue addressed by the NRMC is integrating policy designs into preexisting conservation planning and policies for managing new efforts.

Suggestions are now made to develop this framework further. The economics of information and investment provide the main conceptual and practical guidelines to conservation planning where risk and irreversibility play a key role.

\section{Increasing knowledge}

This NRMC objective seeks to improve knowledge of the impacts of climate change on biodiversity over time horizons where adaptation planning is sensible, to improve understanding of adaptation responses and to increase the capacity to assess costs and benefits of different policy responses. These objectives can be augmented to include improving knowledge of the likely extent of climate change in specific areas. The NRMC also focuses on the need to transmit information to policy makers and the broader community.

Economically efficient investments in information depend on the extent of uncertainty faced, costs of acquiring information and benefits consequent to having better information. As emphasised earlier, there is substantial uncertainty regarding global warming effects and on the resilience and adaptability of biodiversity to climate change. Information about climate change is partly a global public good that is underprovided by private markets because it is costly to generate but can be accessed at low cost. Hence, there is a global case for public investment in long-term meteorological and climate research to gain information 
and efficiency arguments for Australia to contribute to such provisions. There is also a local case for providing region-specific Australian climate change forecasts. At each level a key question is the extent of likely climate change given plausible assumptions about global mitigation responses.

Information on the adaptability of Australian biodiversity is mostly a local public good that will be generated mainly in Australia. This is likely to be more expensive than climatic information as it will be site- and species-specific. Since exhaustive characterisations are impractical, such informational investments require prioritization on the basis of implied threats to biodiversity and probable net rewards.

Climatic and biological information accrues through time with experience, through observing the adaptability of ecosystems, and through science-based learning in fields as diverse as climatology, zoology, botany, conservation biology and so forth. Given learning possibilities there are incentives to monitor developments and to delay acting on developments until information quality improves. While the need to 'wait' is a standard incentive in dynamically-evolving uncertain systems, significant effects of climate change will occur in the shortterm, over perhaps thirty to seventy years. The opposing 'sunk cost' and 'species loss' irreversibilities that were rationalised above in terms of physical investments apply to information investment as well.

Moreover, it might be expected that adaptation strategies could become both more expensive and less effective as the extent of climate change increases. As with the climate change issue as a whole, there are incentives to act promptly on the basis of imperfect information rather than to wait for much more accurate information. This means that policy responses should take the form of closedloop feedback rules reflecting current knowledge and which evolve as knowledge itself evolves.

A particular information concern is to identify 'at-risk' species and habitats and to list them as threatened under legislation. This makes sense if high costs are associated with extinctions. Addressing the extinction issue enables policy authorities to eliminate crucial, complicating irreversibility constraints.

A final specific information concern is to identify climate change effects on the distribution of new and established exotic, as well as native, invasive species. While some species will be damaged by climate change, the survival prospects of others may be improved, thereby damaging the survival prospects of competing species.

\section{Optimising biodiversity impacts}

These impacts are classified by the NRMC into different categories by geographic area, and actions are sought to minimise the harmful effects of climate change in each. One focus is on impacts on hydrological cycles and consequent impacts on inland aquatic and semi-aquatic species. Another looks at impacts on marine, estuarine and coastal ecosystems. A third looks at terrestrial systems. Concern also focuses on minimising the impact of invasive species whether they are exotic or native species. 
There is a range of adaptation investments that can improve the resilience of biodiversity. For the most part, the NRMC emphasises investments building on current conservation efforts. These fall into several areas.

- $\quad$ Policies designed to increase the environmental resilience of existing conservation zones. This includes policies for increasing conservation reserve size, measures to improve and restore streams and aquatic environments, limiting land degradation and invasive pest species and providing fire management regimes. For many conservation efforts the general prescription for policy is for more active management.

- Investments in new reserves that seek to strengthen the capacity of the reserve system as a whole to act as a refuge for vulnerable species that relocate in response to climate change. This might include investments in wildlife corridors that facilitate migrations and the translocation of particular threatened species. An important aspect is to develop partnerships between government and landowners to facilitate linkages and stepping stones to assist biodiversity adaptations. The BushTender scheme for biodiversity buybacks on private land can provide linkages at low cost (Department of Sustainability and Environment, 2000).

- $\quad$ Efforts to protect species whose existence is threatened by climate change. These species require investments as discussed above, but might also call for conservation by means of captive-breeding programs, zoological and botanical gardens or germplasm and seed banks.

If a pessimistic assessment of the likely success of adaptation measures is taken, insurance policies can be adopted to reduce extinction probabilities. The NRMC suppose captive breeding and translocation strategies are expensive compared to adapting current conservation policies. They make sense however if introduced selectively and if seen as fallback insurance options that imperfectly realise conservation objectives should more general programs fail.

Translocation policies require specific analysis since they are complex and expensive.

The radical strategy of assisted relocation involves moving species to climatic zones where they are expected to have improved survival prospects. This policy triggers strong, mixed feelings among conservation biologists because, although the procedure is risky, not undertaking it may condemn species to extinction. Parmesan (2006) reviewed studies on ecological effects of climate change and concludes that many plant species are already now budding earlier in the spring, animals migrate earlier and the ranges of many species are shifting to higher latitudes, as they track climates that suit them. Relocations have occurred through history and are occurring now.

These adjustments have occurred over the past two million years as the planet has swung between ice ages and warmer periods. But the current warming is different as the earth was already relatively warm when it began. It will also now be more difficult for some species to relocate because when the planet warmed at the end of past ice ages, retreating glaciers left behind empty landscapes. Today's species face the obstacle course of cities, farms and other human settlements. Animals and plants will also have to move quickly if they are to keep up with rapid climatic changes.

Many conservation biologists believe, alternatively, that conventional strategies may help combat extinctions from global warming. McLachlan, 
Hellmann and Schwartz (2007) examine this debate. Bigger reserves and corridors connecting them, as envisaged by the NRMC, provides species more room to move. However assisted relocation may be the only way to save some species if done safely and effectively. The basic questions are: Which species to move and where to take them? If numerous species face extinction then prioritization is inevitable. Those selected need to be relocated to regions where they can survive in a warmer climate but simply moving a species is no guarantee it will survive since most species depend on other species for survival. Also, a transplanted species is an invasive one which might harm the original inhabitants so relocated populations may need to be controlled.

Assisted relocation should be a measure of last resort that is used sparingly for species facing overwhelming extinction threats where natural relocation is impossible. But further species relocations will occur and, as species shift their ranges, some will push into preserves that are already refuges for endangered species.

\section{Incorporating strategies into current practice}

Finally, the NRMC action plan examines the integration of thinking about climate change impacts into current biodiversity planning. The premise is that these programs exist so one can build on them. In addition, new land use strategies may need to be developed to accommodate adaptation. To make current conservation efforts responsive to climate change issues:

- $\quad$ Existing conservation strategies must incorporate climate change into monitoring and reporting systems and use this information to provide policy advice on climate change-induced effects on conservation. A particular concern is with rural adjustment policy and links between the action plans for biodiversity and for agricultural adaptations (NRMC, 2006).

- Major issues concern how the national reserve systems can be linked to provide corridors for species migrations in the face of climate change. The weaknesses of traditional conservation planning, based on a set of independent reserves, become transparent with climate change. Integrated, cost-efficient planning measures linked to agricultural land reclamation programs must be developed.

- $\quad$ There is a need to review new land use and reserve planning policies to account for climate change and to make provision for species adaptations. Again there is the need to provide policy advice on these issues.

- Impacts of climate change must be included in listing threatened and endangered species and in developing recovery plans for such species. While emphasis should be on planning at habitat or biome level, flora and fauna species checklists should be used to identify vulnerable species that fall through gaps missed by 'higher level' conservation effort.

These developments belong prior to the derivation of specific investment policies. Their articulation and refinement is the major output of attempts to evaluate adaptive climate change impacts using economics.

Directing policy towards pre-existing conservation efforts is sensible also from the perspective of offsetting effects of uncertainties by emphasising win-win options. Such efforts are useful if anticipated climatic outcomes eventuate but, in 
so far as they strengthen current programs, they will advance conservation objectives even if climate change impacts are less severe than expected. Win-win or 'no regrets' options can also be encouraged by thinking about synergies with agriculture through enhanced conservation and water resource management policies. In some cases, as emphasised in Intergovernmental Panel on Climate Change (2002:2), there are synergies between policies designed to mitigate climate change and policies designed to help biodiversity adapt. Thus environmentally sound energy, agricultural and forestry policies can mitigate the effects of warming and can improve biodiversity adaptability. High-yielding bioenergy plantations, on the other hand, can have adverse impacts if they replace ecosystems with greater diversity.

Adaptive policies lead to payoffs even if anticipated climatic changes are unrealised. These win-win payoffs have the incidental benefit of helping to secure community support for addressing climate change impacts on non-marketed biodiversity.

\section{Final Comments}

A major issue in conserving biodiversity with climate change is the interaction between high risk and irreversibility. Risk provides incentives to invest in information and provides incentives to wait for additional better information. However, extinction irreversibilities can drive an emphasis on dealing promptly with a problem before it becomes severe.

In this setting, utilising adaptation policies to ameliorate climate change impacts makes sense. These policies can be both passive, reflecting observed changes in biological systems, and anticipatory adaptation (Schneider and KuntzDuriseti, 2002). Proactive policies involve strengthening the resilience of biological systems now to deal with climate change impacts in the decades ahead.

As a general proposition it makes sense to rely on a range of policy responses and to view policy as adaptive or closed-loop rather than open-loop responses.

Biodiversity losses are irreversible so it is sensible to be prepared to deal with the worst that can happen. This suggests assigning higher than expected values to biodiversity losses to reflect their option values and to prepare worst-that-canhappen policy responses to climate change effects. Most importantly, it also implies the need to devise back-up plans involving species translocations and captive breeding.

With these uncertainties it makes sense to mix attempts to develop a comprehensive national conservation response with 'test run' projects and case studies at representative and highly endangered and or biodiversity rich conservation sites. These should include a focus on conservation efforts in Australia's single conservation hotspot, namely southwest Western Australia, in critically-threatened Alpine habitats such as the Victorian Alps or the Snowy Mountains, in the rainforest habitats of northern Queensland, in coral reef habitats such as the Great Barrier Reef and in the rangeland areas of southern Queensland or central Western Australia. The costs and benefits of various adaptation policies need to be measured and species loss and sunk cost effects identified in each of 
these settings. Catastrophic risks should be identified and their implications for policy intervention identified.

The case studies should assess the economics of conservation efforts at the various sites, examine existing plans for dealing with climate change and, where necessary, look at cost-minimising options for improving resilience as discussed above. The options examined should include 'doing nothing', investing in improved resilience onsite and, as a limiting policy, arranging species translocations. The 'doing nothing' option is relevant for species whose viability is unthreatened and, using triage arguments, for species whose extinction is inevitable.

Given the information and management expertise possessed and pre-existing conservation resources it makes sense, as the NRMC review suggests, basing adaptation strategies around current strategies. This will reflect the current reserve system and pre-existing efforts to promote conservation on private land, including wildlife corridors. But conservation priorities could change in regions most affected by climate change and this needs to be reflected in planning.

Along with attempts to strengthen pre-existing conservation efforts there needs to be a critical emphasis on identifying where existing efforts are vulnerable or made redundant by climate change impacts. As the NRMC note, to the extent that climate change causes changes in agricultural land values, there are both problems and opportunities for new approaches to planning. 'No regrets' options that draw on synergies between mitigation policies and adaptation policies should be targeted.

\section{References}

Clarke, H. and W. Reed (1994), 'Long-Run Consumption Pollution Tradeoffs in an Environment Subject to Pollution-Related Catastrophic Collapse', Journal of Economic Dynamics and Control 18:991-1010, reprinted pp. 497-516 in M. Hoel (ed) (2004), Recent Developments in Environmental Economics, The International Library of Critical Writings in Economics, Elgar, Cheltenham.

Department of Sustainability and Environment (2006), BushTender - The Landholder Perspective: A Report on Landholder Responses to the BushTender Trial, Department of Sustainability and Environment, East Melbourne.

Dixit A. and R. Pindyck (1994), Investment Under Uncertainty, Princeton University Press, Princeton.

Environment Australia (2001), National Objectives and Targets for Biodiversity Conservation 2001-2005, Commonwealth of Australia, Canberra.

Gaston, K. (1996), Biodiversity: A Biology of Numbers and Difference, Blackwell Science, Oxford.

Grant, S. and J. Quiggin (2006), 'Learning and Discovery', Risk and Uncertainty Program Working Paper R05-7, University of Queensland.

Hughes, L., M. Westoby and E. Cawsey (1996) 'Climatic Range Sizes of Eucalyptus Species in Relation to Future Climate Change', Global Ecology and Biogeograohy Letters 5:23-29. 
Intergovernmental Panel on Climate Change (2002), Climate Change and Biodiversity, IPCC Technical Paper V, Bangkok.

Krutilla, J. (1967), 'Conservation Reconsidered', American Economic Review 47:777-786.

McLachlan, J., J. Hellmann and M. Schwartz (2007), 'A Framework for Debate of Assisted Migration in an Era of Climate Change', Conservation Biology, forthcoming.

Natural Resource Ministerial Council (2004), National Biodiversity and Climate Change Action Plan 2004-2007, Department of Environment and Heritage, Canberra.

Natural Resource Ministerial Council (2006), National Agriculture and Climate Change Action Plan 2006-2009, Department of Agriculture, Fisheries and Forestry, Canberra.

Overpeck, J., J. Cole and P. Bartlein (2005), 'A "Paleoperspective" on Climate Variability and Change', pp. 91-108 in T. Lovejoy and L. Hannah (eds), Climate Change and Biodiversity, Yale University Press, New Haven.

Parmesan, C. (2006) 'Ecological and Evolutionary Responses to Recent Climate Change', Annual Review of Ecology, Evolution \& Systematics 37:forthcoming.

Pindyck, R. (2000), 'Irreversibilities and the Timing of Environmental Policy', Resource and Energy Economics 22:233-258.

Pindyck, R. (2002), 'Optimal Timing Problems in Environmental Economics', Journal of Economic Dynamics and Contro/ 26:1677-1697.

Pindyck, R. (2007), 'Uncertainty in Environmental Economics', forthcoming in Review of Environmental Economics and Policy 1(1):45-65.

Pittock, B. (2003) (ed), Climate Change - An Australian Guide to the Science and the Potential Impacts, Australian Greenhouse Office, Canberra.

Pittock, B. (2005), Climate Change: Turning Up the Heat, CSIRO Publishing, Earthscan, Collingwood.

Preston, B. and R. Jones (2006), Climate Change Impacts on Australia and the Benefits of Early Action to Reduce Global Greenhouse Gas Emissions, CSIRO consultancy report for the Australian Business Roundtable on Climate Change.

Stern Review (2006), The Economics of Climate Change, Cambridge University Press, Cambridge.

Schneider, S. and K. Kuntz-Duriseti (2002), 'Uncertainty and Climate Change', pp. 53-88 in S. Schneider, A. Rosencranz and J. Niles (eds), Climate Change Policy: A Survey, Island Press, Washington DC.

Thomas, C., A. Cameron, R. Green, M. Bakkenes, L. Beaumont, Y. Collingham, B. Erasmus, M. de Siqueira, A. Grainger, L. Hannah, L. Hughes, B. Huntley, A. van Jaarsveld, G. Midgley, L. Miles, M. Ortega-Huerta, A. Peterson, O. Phillips and S. Williams (2004), 'Extinction Risk from Climate Change', Nature 427:145-148.

Wolfson, R. and S. Schneider (2002), 'Understanding Climate Science', pp. 3-51 in S. Schneider, A. Rosencranz and J. Niles (eds), Climate Change Policy: A Survey, Island Press, Washington DC. 
170 Harry Clarke

I thank two anonymous referees for helpful substantive and editorial comments. I also thank Louise Collis and Lee Smith for editorial assistance. I acknowledge research support from The Faculty of Law and Management at La Trobe University. 